regions in question would not supply food sufficient for both parents and offspring - the latter being, at the lowest computation, twice as numerous as the former-unless the numbers of both were diminished by the casualties of travel. But another point must not be overlooked. The most sedentary of birds year after year occupy the same quarters in the breeding season. In some instances this may be ascribed, it is true, to the old haunt affording the sole or the most convenient site for the nest in the neighbourhood, but in so many instances such is not the case, that we are led to believe in the existence of a real partiality, while there are quite enough exceptions to show that a choice is exercised. The same may equally be said of the most migrant of birds, and perhaps the strongest instance that has ever come to my knowledge refers to one of the latter. A pair of Stone Curlews (Edicnemus crepitans) - a very migratory species, affecting almost exclusively the most open country-were in the habit of resorting for many years to the same spot, though its character was entirely changed. It had been part of an extensive rabbit warren, and was become the centre of a large and flourishing plantation. It seems to me, therefore, that among the causes of migration the desire of returning to old haunts must be included.

II. The Mode or Modes of Migration. - This heading is capable of much subdivision. The means of transition are of course found in the bird's wings, but do all birds migrate in the same manner? Nay, more, does the same species of bird migrate in the same manner at all times? And how is its return to the old haunt accomplished with a degree of certainty that in most cases may be called unerring?

That all birds do not migrate in the same manner is pretty plain. Some, as the swallows, conspicuously congregate in vast flocks, and so leave our shores in a large company, while the majority of our summer visitors slip away almost unobserved, each apparently without concert with others.

It is also pretty nearly certain that the same species of bird does not migrate in the same manner at all times. Mr. St. John telis us of the arrival of skylarks on the coast of Norway :- " They come flitting over in a constant stragying stream, not in compact flocks." Yet it is notorious that a little later these same birds collect in enormous flocks, which prosecute their voyage in company. As tencling to the same conclusion, I need hardly do more than refer to the excellent observations of Mr. Knox on the movements of the Pied Wagtail ("Ornithological Rambles," third edition, pp. $81-86)$ and, indeed, to the whole of his remarks on migration, because they must or ought to be known to everyone who takes an interest in the subject. But more than this, it is pretty nearly certain that of the majority of northward migrants in spring the males take the lead, and anticipate the advent of their mates by some days, not to say weeks--a fact which may possibly indicate the existence of another cause of migration to which I have not before alluded-while this peculiarity has never been observed in the autumnal movement.

Then comes the question, How is it that birds find their way back to their old home? This seems to me the most inexplicable part of the whole matter. I cannot cven offer an approach to its ${ }_{i}^{\%}$ solution. There was a time when I had hopes that what is called the "homing" faculty in pigeons might furnish a clue, but my good friend Mr. Tegetmeier has cruelly deprived me of that consolation, declaring that knowledge of landmarks obtained by sight, and sight only, is the sense which directs these birds, with which he is so conversant; while sight alone can hardly be regarded as much of an aid to birds -and there is some reason to think that there are several such - which at one stretch transport themselves across the breadth of Europe. Here I have no theory to advance, no prejudice to sustain. I should be thankful indeed for any hypothesis that would be in accordance with observed facts. They leave no room for chance and not much for counteracting forces. Occasionally the return of the nightingale, the swallow, or other land birds, may be somewhat delayed, but most sea-fowl can be trusted as the almanack itself. Were they satellites revolving around this earth, their arrival could not be more surely calculated by an astronomer. Foul weather or fair, heat or cold, the puffins repair to some of their stations as regularly on a given day as if theirmovements were timed by clock-work. Whether they have come from far or from near we know not, but other birds certainly come from a great distance, and yet they make their appearance with scarcely less exactness. Nor is the regularity with which certain species disappear much inferior; every observer knows how abundant the swift is up to the time of its leaving its summer home, and how rarely it is seen after that time is past. Yet all this, marvellous as it may seem, is farless marvellous than the instinct, or whatever else we may call it, which guides the birds in their voyages, and gives them the power of directing their flight year after year to the same spot. The solution is probably simple in the extreme-possibly before our eyes at this moment if we could but see it-but whosoever discovers it will assuredly deserve to have his name remembered among those of the greatest discoverers of this or any age.

ALFRED NEWTON

\section{COMPETITIVE EXAMINATIONS}

$\mathrm{N}$ so universally substituting Competitive Examination $d$ for the much less perfect systems of patronage and favouritism previously adopted for filling appointments and distributing emoluments, no doubt the step has been in the right direction; but as with all novel systems, the necessary details of its working have not been fully mastered, and we have complaints,--such as from many who have no other recommendations upon which to make selections in scientific appointment, and from the India Civil Service,--that the results are not, in the long run, so successful as could be wished. Many of the objections which were at the outset though to be insurmountable, have been proved to be insignificant and remediable; whilst others, unforeseen and more difficult to overcome, are daily becoming more and more conspicuous.

The most important of these objuctions depends on the fact that it is impossib!e, from the list of succ siful candidates, even when they are classed according to the number of mark; they have obtained, to determine whether they belong to the one or the other of two very different qualities of mind. There are certain students whose chief capacity consists of a very excellent memory 
in combination with a power of discriminating what is, and what is not, important in an examination point of view. These, in the hands of an experienced teacher, an able "craminer," or with well-selected books at their disposal, are able, by dint of hard work, so far to make up for their own deficiency in originating power, as to appear, in an examination conducted on ordinary methods, indistinguishable from those who, by accurate observation and much less reading than themselves, have from their superior capacity been able to obtain the same amount of information. What is the result? Taking an instance in which one of each of these classes competes, one against the other, perhaps the former has come out senior and the latter second in the examination list. The latter knows that he might have done better without much effort, and is in no way injured by being beaten. But the former is in a very different position. He finds himself placed above a man of acknowledged great ability, and from this in his smaller mind he infors that he is greater still, considering that he has beaten all. He goes forth into the world with a conscious and unfounded feeling of power; sets up for being a genius; and though his capacities may be anything but inconsiderable, he completely over-estimates himself. If he is a man who has to get his living entirely by his own work he most probably attempts the highest things; to become a barrister or a physician rather than to follow the routine of a solicitor or a general practitioner, for which in reality he is more suited. When the struggle for life commences in earnest he has the continual mortification of seeing others, to whom he has been led by his examination results to think himself superior, passing him on account of their greater ability. This sours his disposition, depresses him unwarrantably, compels him ultimately to relinquish his higher aspirations, and, as a despondent cynic, makes him take to the more humble line of action which at the time of his success he despised so thoroughly.

This is not an overdrawn picture, its counterpart may be seen on all sides, and many more like it will be forthcoming if some radical change is not made in the method of examination now in vogue. What that change must be deserves the serious consideration of all interested in the progress of every branch of social economy, as well as of those who have the responsibility of filling posts of scientific importance. In this respect we think that the older Universities, Oxford and Cambridge, in their more venerable honour examinations, set by far the best example. How accurately, in many of the colleges, the exact mental capacities of those of its undergraduates who are candidates for honours are known, is also more than surprising to the uninitiated. The reason of this is that the examiners are men of acknowledged ability, and what is as much to the point, they have themselves gone through the same training, with the same objects in view, as those whom they are comparing. The ultimate object of work has no doubt a very important bearing on the manner in which it is undertaken; and it is hardly to be wondered at that in a competition like that for the India Civil Service, in which so painfully large a number of subjects is frequently included by some of the candidates, specialist examiners find it extremely difficult to judge, from the undigested mass of answers they have to com- pare, which is the least bad of the candidates before them. In institutions like the University of London, the system of offering scholarships to be competed for in special "honours" examinations, which follow those for simply obtaining the degree, has, in many cases we could refer to, had the same injurious effect of giving men a false estimate of their own practical power of getting on in life; and whether in the long run the older method of conferring degrees after a pass examination only, without any associated pecuniary reward, is not the best is still a subject quite sub judice. In Medical Science this is particularly the case, for in it, more than or as much as in any other, a purely theoretical knowledge of any department of Chemistry, Physics, or Biology, is but of slight value in comparison with the experience of the bed-side, when the commencing practitioner is called upon to diagnose and prescribe without any assistance from others.

In the Universities of Oxford and of Cambridge we have an opportunity of watching the working of the two clifferent systems of examining competing candidates. In the former the lists appear with the names in each arranged alphabetically in three or four classes, and not according to the actual merit in each class. The public are therefore told by this method the average standard to which a man has risen, and no more; for the rest they are left to judge by other entirely independent and perfectly voluntary performances by which he has the opportunity of exhibiting the quality of his ability. In Cambrid ge the tripos lists place each man in exactly his place with resard to the other men of his year who have taken up the same subject as himself, and every attempt is made to maintain all the triposes at such a standard that corresponding classes indicate similar ability. From the remarks with which we commenced it is evident that the Oxford system has many advantages; and that the other is liable to lead to the injurious result we have mentioned, which in that particular case it does not, on account of the antiquity of the system and the extremely careful way in which the examinations are conducted.

It is the fashion in most modern examinations to include a large number of subjects, many of which may be taken up by each candidate. This, no doubt, is a mistake in many instances. It is not so much information that is wanted in a young man-that will come when the stimulus for showing it becomes greater, but the exhibition of mental capacity; and with examiners of any worth, who have had any experience, it is not at all difficult to estimate the powers of candidates from a very few answers in a very few subjects, especially if any vivâa voce and practical questions are included.

A competitive examination should therefore have for its object the estimation of the power of the candidate, and that only. It should be so conducted as to place him on a standard table in such a position that if it were possible from a physical examination of his brain to judge of his brain capacity, the results of the two methods would coincide. This can be best attained by restricting the examination to a few subjects ; by asking questions which call for method in their answers rather than fact ; and by having able examiners who are acquainted with future work to be expected of the candidate. Candidates thus selected in the long run must certainly be found more satisfactory than those chosen by any other method. 